\title{
BOCCACCIO Y OTÁLORA EN LOS ORÍGENES DE LA NOVELA CORTA EN ESPAÑA
}

Aunque durante el Renacimiento no desaparece la tradición ejemplarizante y medieval del relato, se difunde como novedad más significativa la propuesta que desde el siglo XIV adelanta Boccaccio $^{1}$. Frente a los ejemplarios como El conde Lucanor, la función predominante de los cuentos enmarcados en el Decamerón ya no es la de ilustrar el proceso de razonamiento, sino más bien la de relajar o entretener el ocio de los interlocutores. El mencionado cambio, aunque no sea privativo de ninguna época, se difunde sobre todo durante el período renacentista cuando, como se ha dicho, "la narración constituye una finalidad en sí misma"2. En conjunto, los relatos de Boccaccio care-

${ }^{1}$ Durante el siglo xvI, se editan con éxito colecciones medievales de cuentos como Calila, Sendebar, El conde Lucanor y, sobre todo, Isopete. Véase, por ejemplo, M. J. LACARRA, "Pervivencia y transmisión del cuento medieval en la Edad de Oro", en La edición de textos. Actas del I Congreso Internacional de Hispanistas del Siglo de Oro, Tamesis, London, 1990, pp. 261-269. Hay que advertir, sin embargo, que en algunos casos, el didactismo característico de estas colecciones, por lo menos en teoría, no se mantiene, como sucede en las llamadas "fábulas colectas" y "añadidas" del Isopete ystoriado (Toulouse, 1488), eds. V. A. Burrus y H. Goldberg, Madison, 1990, pp. 137-163. Véase Domingo Ynduráin, "Historia y ficción en el siglo xv", en prensa. Agradezco al profesor Ynduráin las observaciones sobre estas páginas, redactadas en una versión previa con motivo de la amable invitación del profesor Juan Montero para asistir al curso (septiembre, 1996) sobre prosa de ficción en el Siglo de Oro, celebrado en la Universidad de Sevilla.

${ }^{2} \mathrm{~V}$. Shklovski, "La construcción de la nouvelle y de la novela", Teoría de la literatura de los formalistas rusos, ed. T. Todorov, Siglo XXI, Madrid, 1970, p. 142. Según advierte W. PABST, La novela corta en la teoría y en la creación literaria, Gredos, Madrid, 1972, p. 28, el desplazamiento de lo didáctico a lo ameno "no se halla vinculado a una época, aunque encontró evidentemente condiciones muy favorables en el umbral que separa a la Edad Media del Renacimiento”. 
cen de ejemplaridad directa, el placer y el deleite constituyen su principal finalidad, que marca la "radical novedad" del Decamerón ${ }^{3}$. En la misma línea trazada por Boccaccio, hay una serie de obras relacionadas o no con el Decamerón en las que se exalta el relato como vehículo de entretenimiento principalmente. Así, en el Convivium Fabulosum de 1524, escrito también en forma dialogada, Erasmo abandona su habitual tono didáctico e introduce un grupo de amigos que sólo pretenden entretenerse durante la comida contando, como dice uno de los comensales, ridiculas fabulas ${ }^{4}$. El marco convival justifica el tono risible de los relatos, que se cuentan por diversión durante la sobremesa. Algo parecido sucede, como veremos, en los viajes cuando se narran cuentos para entretenerse durante el camino.

El relato de entretenimiento asimismo se impone como parte de la educación cortesana y, en general, de lo que se ha llamado "adiestramiento" social ${ }^{5}$. En algunos tratados educativos de la época bien conocidos, como El Cortesano de Castiglione publicado en 1528 y traducido por Boscán en 1534, "saber contar bien un cuento" se considera como una de las habilidades que el cortesano debe desarrollar en determinados momentos ${ }^{6}$.

${ }^{3}$ Como advierte D. Ynduráin: "Es el placer libre de contar - y de leerlo que marca la radical novedad de Boccaccio", Humanismo y Renacimiento en España, Cátedra, Madrid, 1994, p. 354. Cf. E. Auerbach, Mimesis, F.C.E., México, 1950, pp. 205 ss.

${ }^{4}$ Véase M. Bataillon, "Erasmo cuentista. Folklore e invención narrativa”, Erasmo y el erasmismo, Crítica, Barcelona, 1983, pp. 80-109.

${ }^{5}$ M. P. PAlomo, La novela cortesana. (Forma y estructura), Planeta, Barcelona, 1976, p. 55: "Las colecciones renacentistas se destinan a un entretenimiento y adiestramiento sociales; lo que debe destacar en ellas es el ingenio, y van a ser, en sí, una práctica de cultos hombres renacentistas, y destinadas, por tanto, a una sociedad de aspiración cortesana”. Cf. A. PRIETO, La prosa española del siglo xvi, Cátedra, Madrid, 1986, t. 1, pp. 17-59; y A. C. Soons, Haz y envés del cuento risible en el Siglo de Oro, Tamesis, Madrid, 1976, pp. 24-25, donde habla también de la facetudo renacentista, "un concepto totalmente nuevo en torno a los cuentos", en relación con las teorías retóricas del siglo xvi. Según matiza Yndurárn, "Cuento risible, folklore y literatura en el Siglo de Oro", RDTP, 34 (1978), 112-113: "es una moda culta que afecta a una parte de la sociedad", moda que coexiste con la tradición de las colecciones orientales y con la difusión de cuentecillos más o menos folklóricos.

${ }^{6}$ En adelante, cito El Cortesano por la traducción de J. Boscán (1534), ed. M. Pozzi, Cátedra, Madrid, 1994, con la indicación en romanos del libro, seguido del número de epígrafe o epígrafes correspondientes. El libro de Castiglione ejerce influencia en otros tratados educativos como el Galateo de Giovanni della Casa traducido al castellano en 1593 por Lucas Gracián Dantisco, El Galateo español, ed. M. Morreale, CSIC, Madrid, 1968, donde tam- 
Castiglione propone en su diálogo, como parte de las actividades del perfecto cortesano, el referir oportunamente "gracias" y "burlas". Así, uno de los interlocutores de El Cortesano, miser Federico Fregoso, explica: "sepa con una buena dulzura hacer que huelguen con él los que le oyeren, y levantallos discretamente con motes y gracias y buenas burlas y hacellos reír de manera que, sin ser jamás pesado, sea gustoso para los que lo hubiere de ser" (II, 41). Como en el Decamerón, se exalta el relato de entretenimiento, haciendo hincapié en su valor risible y cómico. Para ilustrar la propuesta, en el libro segundo de $\mathrm{El} \mathrm{Cor-}$ tesano, se refieren varios chistes, facecias y burlas para "hacer reír" (II, 47 ss.). Además, los interlocutores de Castiglione aluden con relativa frecuencia a las novelas del Decamerón, como la del cura de Varlungo (II, 49) o las de Galandrino (II, 49 y II, 89), entre otras (II, 92). Castiglione establece, por tanto, un vínculo entre el ideal de "urbanidad" (II, 43), traducido por Boscán, y la narrativa de Boccaccio, siempre dentro de la tradición dialógica, pues hay significativas semejanzas entre el diálogo marco que propicia la reunión de los interlocutores en El Cortesano y el del Decamerón.

En la literatura castellana, a imitación de Castiglione, Cristóbal de Villalón compone entre 1535 y 1556 un manual edu-

bién se habla de los cuentos, especialmente los caps. 12 ("Del hablar continuado") y 13 ("De las novelas y cuentos"). La concepción de la novella como actividad social propia de las veladas cortesanas aparece también, entre otros ejemplos, en el Dialogo de' Giuochi che nelle vegghie sanesi ssi usano di fare (1572) de Girolamo Barbagli, trad. y ed. parcial de M. J. Vega Ramos; La teoría de la novela en el siglo xvi: la poética neoaristotélica ante el "Decamerón", Cáceres, 1993, pp. 146-160. Por su parte, Lorenzo Palmireno, El estudioso cortesano, Valencia, 1573, aborda la cuestión en los epígrafes "Estudioso en conversación” y "Del estudioso convidado". En el segundo epígrafe, por ejemplo, ofrece el siguiente consejo (modernizo la acentuación y, ligeramente, la puntuación y la ortografía del original): "Dexa un rato essa gravedad estoyca, cuéntales con que se recreen, cosas que son poco familiares, como la historia de Don Ioan de Mendoça y la Duquesa, o la de Rhomeo y Iulieta en Verona, la de Edoardo y Elips Condesa de Salberique. Están en francés, son muy suaves, durará de contar cada una media hora, sin que se fatiguen los oydores; si tú guardas los affectos. Llámase el librico Les histoyres tragiques, in 16. anno 1557. Si no hay modo para cosa larga, hallarás, cuentos cortos en el librico que se intitula, Facecies, et motz subtils d'acuns excellens espritz, et tres nobles, en françozs, y en italiano in 8. Lyon. Si los vees affectados a hablar de sotilezas de manos, acuérdate de Sylvia de Eutrapelias de Moya, en Valladolid, año 1557. Experimente Ioachimi Fortii, las Novelas de Masucio Salernitano, o mi borrador que tienes arriba en el de la Aldea, de segunda impressión”. 
cativo, con el título de El Scholástico, significativamente escrito en forma de diálogo al modo de El Cortesano ${ }^{7}$. Villalón señala asimismo la necesidad de hacer más agradable la conversación en sociedad, para que el escolástico que forman el rector de la Universidad de Salamanca y sus amigos, como reza el título del capítulo último, sea "graçioso y apazible" (libro IV, cap. 17). Es necesario que el escolástico sepa durante los banquetes motejar y decir "cuentos, fábulas y façeçias" porque, como explica Alvaro de Mendoza, uno de los interlocutores de El Scholástico:

el día de oy es entre los hombres vn vso tan común entre qualesquiera condiçiones de varones: en pasatiempos de combites o çenas no pasan su tiempo en más, para su conversaçión y plazer. Préçianse todos de se motejar entre sí; y entre su hablar vienen a dezir motes y graçias sabrosas y apazibles, y a dezir cuentos, fábulas y façeçias con las quales se quieren recrear, y prinçipalmente quando el combite se ha çelebrado en vn deleytoso huerto o jardín, el qual es lugar más aparejado para este género de recreaçión, como nos es agora a nosotros éste ${ }^{8}$.

El diálogo de Villalón está ambientado en un paraje ameno, durante la sobremesa, como tiempo apropiado para la recreación y para el placer. El marco dialogado de El Scholástico coincide, de manera significativa, no sólo con el Convivium de Erasmo, sino también con el marco de El Cortesano y, por supuesto, con el del Decamerón. Como en el caso de Boccaccio y de Castiglione, la reunión amistosa sirve de pretexto para introducir varias facecias y anécdotas risibles, la mayoría de las cuales se narran en el capítulo último de El Scholástico, como la del cazador de grullas, la de la tinta, la del truhán que vende el ca-

${ }^{7}$ La segunda redacción de El Scholástico, según lo establecido por R. A. KERR, se completa no después de 1556: "El «problema Villalón» y un manuscrito desconocido de El Scholastico", Clavileño, 6 (1995), 15-22, y "Prolegomena to an edition of Villalón's Scholástico", BHS, 32 (1955), 130-139 y 203-213.

${ }^{8}$ El Scholástico, ed. R. Kerr, CSIC, Madrid, 1967, p. 219. M. T. СAcho Palomar, "Cuentecillo tradicional y diálogo renacentista", en Formas breves del relato. (Coloquio. Febrero de 1985), eds. Y. Fonquerne y A. Egido, Universidad, Zaragoza, 1986, p. 121. Para los entretenimientos cortesanos, en la línea de Castiglione, véase también El Cortesano (1561) de Luis Milán cuya acción se ambienta en la corte valenciana de Germana de Foix, cuando los caballeros y damas intercambian chistes, cuentos, poesías, leyes de amor, etcétera. 
ballo, la del mercader, etc. ${ }^{9}$. La inclusión de relatos risibles y cómicos se justifica precisamente dentro del marco elegido, en el que los interlocutores tan sólo pretenden entretenerse bien sea durante la sobremesa, motivo que aparece en El Scholásti$c 0^{10}$, o bien con otros pretextos que pueden aparecer asimismo en algunas colecciones de relatos renacentistas. Como veremos, se cuentan también para acortar las noches de invierno o para aliviar el tedio del camino.

Precisamente, una de estas colecciones más tempranas lleva el significativo título de El sobremesa y alivio de caminantes. Se publica en 1563, aunque en ella su autor, Timoneda, se limita a editar los cuentos sin marco, simplemente yuxtapuestos, como hace también con posterioridad en el Buen aviso y portacuentos, de 1564, y en El Patrañuelo de 1567, colección esta última directamente relacionada con el Decamerón ${ }^{11}$. A pesar de la influencia

${ }^{9}$ Se incluyen otros relatos breves al inicio de El Scholástico, como el del estudiante Durango (lib. I, cap. 3) que aparece también en El Crotalón (canto X), el de Menipo y Menedemo (lib. I, cap. 4), Jerónimo y Luis (I, 5), Toxaris (I, 6). También hay varios relatos en el cap. 13 del lib. II. Cf. J. M. Martínez Torrejón, "Valor retórico del relato corto en El Scholástico de Cristóbal de Villalón", en Estado actual de los estudios sobre el Siglo de Oro. Actas del II Congreso Internacional de Hispanistas del Siglo de Oro, Universidad, Salamanca, 1993, t. 2, pp. 635-639.

10 El motivo de la sobremesa aparece con anterioridad en la Segunda Celestina (1534) de Feliciano de Silva, ed. C. Baranda, Cátedra, Madrid, 1988, p. 421. Dice Elicia: "que sobremesa, ya que hemos comido, cuentes al señor Grajales y a mi prima el cuento de lo que te acaeció".

11 Dice M. Menéndez Pelayo, "Cuentos y novelas cortas", Orígenes de la novela, Aldus, Santander, 1943, t. 3, p. 27: "Antonio de Torquemada, en sus Coloquios satíricos (1553), y Juan de Timoneda, en su Patrañuelo (1566), son los primeros cuentistas del siglo xvi que empiezan a explotar la mina de Boccaccio”. La patraña segunda de Timoneda deriva del Decamerón (X, 10); se trata de la famosa novela de Griselda, difundida a partir de la traducción latina de Petrarca y que se narra también en los Cuentos de Canterbury, fue traducida al catalán por B. Metge y al castellano con el título de Castigos y doctrinas que un sabio daba a sus hijas (siglo xv). Véase C. B. Bourland, "Boccaccio and the Decamerón in Castilian and Catalan literature", RHi, 12 (1905), 1-232. Las otras dos patrañas que derivan del Decamerón son la decimoquinta (Dec II, 9) y la última, el cuento de los dos amigos (X, 8. Se cita la obra de Boccaccio por la trad. cast. de 1496, ed. M. Olivar, Planeta, Barcelona, 1982 , sin más que indicar entre paréntesis el número de jornada, en romanos, seguido del de la novela que corresponde). Las historias que Timoneda toma de Boccaccio son historias ejemplares de amor y de amistad. No faltan, sin embargo, en El Patrañuelo argumentos puramente cómicos y risibles porque, como advierte W. KRöмer (Formas de la narrativa breve en las literaturas románicas hasta 1700, Gredos, Madrid, 1979, p. 208), Timoneda "no cuenta 
de Boccaccio, sin embargo, durante el siglo xvi aún no se había popularizado en la literatura castellana el motivo del marco dialogado decameroniano para introducir relatos breves y novelas cortas. Este tipo de marco no hace su aparición probablemente hasta 1609, cuando se publican las Noches de invierno de Eslava. Así, durante el siglo XvI, se suceden las colecciones de relatos breves que se editan sin marco alguno, como Las seiscientas apotegmas (1596) de Rufo, la Filosofia vulgar (1568) de Mal Lara, los llamados Cuentos de Garibay, los de Luis Pinedo o la Floresta espanola (1574) de Melchor de Santa Cruz.

Sin embargo, al lado de estas colecciones, hay otro tipo de obras en la literatura castellana del siglo xvI cuya estructura se asemeja a la del Decamerón, por interpolar también relatos breves dentro de un marco dialogado, aunque en realidad Boccaccio agrupa los relatos más que interpolarlos. Esta tradición, relacionada con el modelo dialógico de El Cortesano de Castiglione, se hace patente asimismo en algunos coloquios lucianescos y erasmistas cuya importancia ha sido puesta de relieve en los últimos años, a partir de la tesis magistral de M. Bataillon, Erasmo y España, publicada por primera vez en 1937. Cabe citar especialmente tres diálogos anónimos compuestos a mediados del siglo XVI, el Diálogo de las transformaciones de Pitágoras (d. 15311532) y, sobre todo, El Crotalón (d. 1555) y el Viaje de Turquía (1557) ${ }^{12}$. A esta serie, podemos añadir ahora los Coloquios de Palatino y Pinciano de Juan de Arce de Otálora, que presentan significativas similitudes con los diálogos citados. Lamentablemente, M. Bataillon no llegó a estudiar la obra de Otálora, a pesar de que tuvo noticias de su existencia ${ }^{13}$. De hecho, los Colo-

para instruir, como antes había hecho la literatura española del Ejemplo, sino para deleitar".

12 M. Bataillon, "La floración de diálogos", Erasmo y España, trad. A. Alatorre, F.C.E., México, 1966, cap. 12. Del anónimo Diálogo de las transformaciones de Pitágoras, hay por fin una edición fiable, a cargo de Ana Vian, Sirmio, Barcelona, 1994. Agradezco a la profesora Vian la lectura de estas páginas, así como su amabilidad al facilitarme copia del estudio de Rotunda citado en la nota 30 .

13 Pionero en la alusión a los Coloquios de Otálora es el artículo que E. AsEnsio publica en el AEM, 6 (1972-73): "Notas sobre la historiografía de Américo Castro con motivo de un artículo de A. A. Sicroff”, incluido luego en la España imaginada de Américo Castro, Crítica, Barcelona, 1992, pp. 179182 , cuando se refiere a "esta obra inédita, prolija pero interesante que abunda en curiosas noticias y opiniones expuestas con la libertad de que hace gala el diálogo erasmiano". Con anterioridad, existe una tesis inédi- 
quios de Palatino y Pinciano, prácticamente desatendidos por la crítica excepto en algunas notas aisladas, se editó por primera vez en 1995.

Tanto por los méritos literarios de la obra de Otálora, como por ser poco conocida todavía, voy a detenerme en los citados Coloquios, cuyo texto se ha conservado en cuatro copias manuscritas, las tres primeras fechadas en el siglo xvi y la última, que es una copia parcial, en el siglo XVIII ${ }^{14}$. Durante el siglo XVI hubo diversas redacciones de los Coloquios de Palatino y Pinciano cuyas variantes no carecen de interés. Además, parece posible fijar la composición de la obra de Otálora con posterioridad a 1550 y, si hacemos caso de la cronología interna, el proceso de redacción debió de finalizar pocos años después ${ }^{15}$. En última instancia, hay que tener presente que el autor, un prestigioso letrado que desarrolla su carrera durante el reinado de Carlos V y de Felipe II, fallece en $1561^{16}$.

ta, en su mayor parte descriptiva, de Norine P. O'Connor, Juan de Arce de Otálora: "Coloquios de Palatino y Pinciano", an Erasmian dialogue of the sixteenth century. A critical analysis of the unpublished manuscript, University of Texas, Austin, 1952, que he podido consultar recientemente, gracias a la mediación de José Luis Ocasar.

14 Juan de Arce de Otálora, Coloquios de Palatino y Pinciano, ed. J. L. Ocasar Ariza, Biblioteca Castro-Turner, Madrid, 1995, quien reproduce el manuscrito de la British Library, Col. Egerton, 578. En adelante, cito por esta edición sin más que indicar entre paréntesis el número de la jornada, en romanos, seguido del número de estancia.

${ }^{15}$ En su análisis, concluye O'Connor: "the aproximate time of composition may be determined from internal evidence as being no earlier than 1550 or later than 1555 " (p. 10). Palatino y Pinciano visitan en Tordesillas a Juana la Loca (que fallece en 1555). Además, citan los Coloquios de Mexía, impresos en 1547. Pinciano afirma incluso que el mundo "pasa ya de mil y quinientos y cincuenta" (Coloquios XI, 4).

${ }^{16}$ Referencias a las actividades de Otálora como letrado hay en algunas obras: J. FAYARD, Los miembros del Consejo de Castilla (1621-1746), Siglo XXI, Madrid, 1982, p. 255; J. M. Pelorson, Les "letrados", juristes castillans sous Philippe III, Université, Poitiers, 1980, pp. 141, 223; R. L. Kagan, Lawsuits and litigants in Castile (1500-1700), University of North Carolina Press, Chapel Hill, 1981, pp. 181-186. Juan Arce de Otálora, vallisoletano de antecedentes nobiliarios, perteneció a la clase de los letrados o juristas ascendente en tiempos de Felipe II. Su trayectoria profesional estuvo ligada a la administración de justicia, después de haber estudiado leyes en la Universidad de Salamanca, donde era colegial mayor del Colegio del Arzobispo, y después de haber ocupado la cátedra de Instituta en Valladolid y luego en Salamanca. En 1540 fue nombrado fiscal de la Chancillería de Granada y en 1551 fue oidor, primero en la Audiencia granadina y a partir de 1559, en la 
La temprana fecha de composición de los Coloquios de Palatino y Pinciano, entre 1550 y 1561 como máximo (por las mismas fechas en las que Villalón finaliza El Scholástico), hace más interesante la aportación de Otálora a la historia de la novela corta durante el Renacimiento, ya que sería anterior a Timoneda y a la mayoría de las colecciones que habitualmente se catalogan dentro del género ${ }^{17}$. Su redacción coincide, además, con la de El viaje de Turquía y la de El Crotalón, obras con las que los Coloquios de Otálora presentan no pocas similitudes genéricas. Pertenecen los Coloquios de Palatino y Pinciano a la tradición del diálogo erasmista, con la que también se relaciona directamente El viaje de Turquía. Además, hace uso Otálora del marco dialogado para intercalar en el transcurso de la conversación, al hilo de la misma, varios relatos breves de modo parecido a como sucede en El Crotalón ${ }^{18}$.

de Valladolid. Fue consultor del Santo Oficio y, además de haber escrito los Coloquios de Palatino y Pinciano, compuso una Summa nobilitatis Hispaniae que se publicó en Granada (1553) y se reeditó en 1559, 1570 y 1613. Véase J. L. OCASAR, "Un humanista del siglo xvi: Juan de Arce de Otálora", en Humanismo y Cister. Actas del I Congreso Nacional sobre Humanistas españoles, ed. F. R. de Pascual, Universidad, León, 1996, pp. 379-387.

17 Véase el catálogo que, por ejemplo, establece J. M. LASPÉras, La nouvelle en Espagne au Siécle d'Or, Université, Montpellier, 1987, pp. 15 ss.: Novella que Diego de Cañizares de latyn en romance declaró y trasladó de un libro llamado "Scala Coeli" (mediados del siglo xv), Tragedia de Mirrha (1536) de Cristóbal de Villalón, El Abencerraje (1561), El Patrañuelo (1567) de Timoneda, Novelas de las madejas de fray Melchor de la Serna, novelas incluidas en el Guzmán de Alfarache (1599) de M. Alemán: Ozmín y Daraja, Dorido y Clorinia, Dorotea y Bonifacio. Se podría completar con el panorama trazado por Menéndez PELAYO, "Cuentos y novelas cortas", Orígenes de la novela, y con otros repertorios: E. Place, Manual elemental de novelística española. Bosquejo histórico de la novela corta y el cuento durante el Siglo de Oro, V. Suárez, Madrid, 1926; C. B. BOURLAND, The short story in the seventeenth century with a bibliography of the novella from 1576 to 1700, B. Franklin, New York, 1973, pp. 87-101, o la antología editada por J. Fradejas Lebrero, Novela corta del siglo xvi, Plaza y Janés, Barcelona, 1985. Ninguno de estos autores alude a los cuentos interpolados en los Coloquios de Palatino y Pinciano. Cf. M. Chevalier, "De los cuentos tradicionales a la novela picaresca", Folklore y literatura. El cuento oral en el Siglo de Oro, Crítica, Barcelona, 1978, pp. 120-153. Chevalier cita los Coloquios de Otálora, como antes había hecho E. Asensio, por la copia parcial del siglo XVIII mencionada arriba.

18 Afirma Ana Vian en su ed. cit., Diálogo de las transformaciones, p. 130, nota: "Desde el erasmismo de la primera mitad de siglo se cultiva el diálogo asociado a formas narrativas breves, procedimiento ya practicado por Platón y Luciano, y recogido - aunque de diferente forma- por Castiglione y por 
En los Coloquios de Palatino y Pinciano, a través de la conversación amistosa entre los dos interlocutores, se pretende exponer con propósito didáctico la vida del estudiante de derecho durante la carrera hasta el doctorado y, con posterioridad, las distintas salidas profesionales: Pinciano cursa derecho civil en la Universidad de Salamanca y Palatino, canónico. Sin embargo, al lado del curriculum, los dos estudiantes hablan de otros numerosos temas en sus conversaciones, en las que además intercalan el relato de anécdotas, facecias y aun novelas breves. Como he estudiado ${ }^{19}$, los relatos interpolados en los Coloquios de Palatino y Pinciano provienen de varias fuentes literarias, algunas bien identificadas, como los Apotegmas y los Coloquios de Erasmo, el florilegio de Valerio Máximo, la Historia Natural de Plinio, las facecias de Poggio, etc. Por lo general, Palatino y Pinciano prefieren el relato concebido como fuente de entretenimiento, al igual que los interlocutores de Boccaccio. Aunque pertenecen a diferentes tradiciones literarias, como veremos, hay algunos paralelismos significativos entre el Decamerón y los Coloquios de Otálora, además de las citas explícitas ${ }^{20}$.

Palatino y Pinciano, durante su viaje de ida y vuelta entre Salamanca y Valladolid, se entretienen contando cuentos para

Erasmo mismo; éste, en sus Colloquia somete a los interlocutores a la amplificatio específica del diálogo". De la misma autora, "El Diálogo de las transformaciones de Pitágoras, la tradición satírica menipea y los orígenes de la picaresca: confluencia de estímulos narrativos en la España renacentista" (en prensa). Dentro de la amplificatio del diálogo, conviene distinguir entre el modelo lucianesco al que pertenece el diálogo "de transformaciones" y aquellas obras en las que se explotan argumentos derivados de los novellieri. Aunque pueden coincidir ambas corrientes, como sucede en El Crotalón, el gusto por la narración manifiesto en las obras relacionadas con Boccaccio y con la narrativa italianizante, en general, es diferente al tipo de relato con implicaciones principalmente satíricas que predomina en los diálogos lucianescos y en los Colloquia de Erasmo, con marcada intención reformista en este último caso.

${ }^{19}$ Véase "Las formas del relato breve en los Coloquios de Palatino y Pinciano", RLit, 54 (1992), 75-99.

${ }^{20}$ Como dice N. P. O'Connor (op. cit., p. 71): "It is interesting to note that in 1550 Arce de Otalora frequently mentions the Decameron and refers to Boccaccio as the author of novelas". Así, por ejemplo: "Allá cuenta Juan Boccaccio, entre sus novelas, de un Amón que, siendo naturalmente insensato y bobo, de una sola vez que vio a una dama hermosa, llamada Figenia, durmiendo en el campo, se enamoró della. Y los amores hicieron en él tan notable operación que de tonto y bestial vino a ser hombre discreto y muy avisado" (Coloquios VI, 7). Cf. Decamerón I, 5. 
"alivio" del camino. El motivo, que se conoce como "alivio de caminantes", a partir del título de la colección que Timoneda publica en 1563, se puede remontar hasta los Cuentos de Canterbury, pero también aparece ocasionalmente en el Decamerón: "Señora, si a vos place, yo os llevaré gran parte del camino a caballo con una de mis novelas muy graciosa en manera que vos no sintáis el trabajo del caminar" (VI, 1). En los Cuentos de Canterbury, el planteamiento es general: "Mi propuesta es, en cortas palabras, que cada uno de nosotros, para sobrellevar mejor el camino, relate dos cuentos a la ida y dos a la vuelta de Canterbury"21. En la literatura castellana, además de otras referencias, aparece aludido el motivo en El Scholástico:

Y acontesce acaso que, por no sentir la fatiga de algún largo camino, procuran los hombres vsar este género de plazer ["vienen a dezir motes y graçias sabrosas y apazibles y a dezir cuentos, fábulas y façeçias"] quando van en compañía, porque con él se haze el cansançio del camino menos sentir (p. 219).

De acuerdo con esta costumbre, las conversaciones entre los dos estudiantes junto con los relatos intercalados en los Coloquios de Palatino y Pinciano se organizan en torno al motivo del "alivio de caminantes", que encuentra uno de los primeros y más acabados ejemplos españoles en la obra compuesta por Otálora aproximadamente cincuenta años antes de que se edite el Viaje entretenido (1603) de Agustín de Rojas, El Pasajero (1617) de Suárez de Figueroa o incluso el Guzmán de Alfarache, en cuya primera parte, publicada en 1599, se introduce la novela de Ozmín y Daraja para "entretener el camino con algún alivio" 22 .

${ }^{21}$ Cuentos de Canterbury, trad. J. Lamarca, Planeta, Barcelona, 1984, p. 15. Por otra parte, el motivo literario se remonta hasta el Banquete de Platón, según A. Scobie, "Comes facundus in via pro vehiculo est", $R F, 84$, (1972), 583584. Aparece también al inicio de El asno de oro de Apuleyo, cuando Lucio va camino de Tesalia. En poesía, aparece por lo menos desde el idilio séptimo de Teócrito, en el que Simíquidas le propone al cabrero Lícidas que compartan el camino cantando los dos canciones pastoriles. El motivo es imitado en la Bucólica IX, 64 de Virgilio y en la Égloga III, 289-296 de Garcilaso: "dos pastores que venían cantando /...haciendo su trabajo menos grave", entre otros ejemplos.

${ }^{22}$ Guzmán de Alfarache, ed. J. M. Micó, Cátedra, Madrid, 1987, t. 1, p. 213. Reaparece el motivo en el relato del mozo del pícaro (primera parte, II, 9) "por alivio del camino". Cf. El viaje entretenido, ed. J. P. Ressot, Castalia, Madrid, 1972, "que yo, Ríos y Solano contaremos algún cuento, y con esto 
En relación también con el motivo que organiza el marco de los Coloquios de Palatino y Pinciano, los relatos más elaborados de Otálora tienen como principales protagonistas a viajeros. Esta coincidencia es evidente sobre todo en los cuatro cuentos o novelas cortas ${ }^{23}$ que abren y cierran los Coloquios de Palatino y

entretendremos el camino" (p. 80); diálogo en el que se interpola también la novela de Leonardo y Camila con el mismo motivo: "Y como la prolijidad del camino (como agora el nuestro) les diese materia para procurar divertirse en alguna cosa de gusto" (p. 383). En El Pasajero, ed. M. I. López Bascuñana, P.P.U., Barcelona, 1988, se advierte en la introducción: "trataron de aliviar el cansancio de la ociosidad con diferentes pláticas” (t. 1, pp. 58-59). Otros testimonios aducen M. Chevalier y P. Cuartero en la introd. a su ed., Buen aviso y portacuentos, Espasa-Calpe, Madrid, 1996, pp. 21-22. Se podría añadir también el manuscrito de Pedro de Salazar reseñado por J. M. BLECuA, "Notas para la historia de la novela en España", Serta Philologica F. Lázaro Carreter, Cátedra, Madrid, 1983, t. 2, pp. 1-95.

23 En la actualidad cuando hablamos de novela nos referimos a la novela larga. En cambio, en español antiguo (durante los siglos XVI y XVII), la acepción corriente de novela era la de 'novela corta'. Aparece el vocablo a partir de Santillana, Comedieta de Ponza (estr. XLV): "fablavan novelas e plazientes cuentos". El término se aclimata en castellano sobre todo a partir del Decamerón, como un italianismo (novella) que tiene el significado de "novela corta'. No existe el equivalente del italiano romanzo, que aquí es "libro", "historia", etc. Como se sabe, cuando Cervantes afirma en el prólogo a sus Novelas ejemplares: "yo soy el primero que he novelado en lengua castellana" no se refiere al Quijote, sino a sus doce novelas cortas. En español antiguo, novela es más o menos equivalente de cuento, y así se utiliza indistintamente por varios autores, como Pedro de Salazar, en su colección dedicada a Felipe II (compuesta entre 1558 y 1576, cf. J. M. BlecuA, art. cit.): “cuentos, que los ytalianos llaman novellas". También lo hace Juan de Valdés, Diálogo de la lengua, ed. J. M. Lope Blanch, Castalia, Madrid, 1976, p. 139: "decimos... cuento por novela"; en la trad. de la Zucca del Doni (1551), ed. facs., Puvill, Barcelona, 1981, p. 11, se dice: "El Boccaccio, por el consiguiente, tratando de excelentes y altas cosas, llamó su libro novelas o cuentos"; Covarrubias, s.v. NoveLA, consigna: "un cuento bien compuesto o patraña para entretener los oyentes, como las novelas de Boccaccio"; Gracián Dantisco, Galateo español (1593), traduce al principio novella por cuento, pero luego lo acompaña con el término castizo: "novelas o cuentos" (véase el glosario de M. MORREALE, ed. cit.); Lope en sus Rimas (1602) dice: "cuentos y novelas" y en Las fortunas de Diana (1621): "menos discreto que el de agora, aunque de más hombres sabios, llamaban a las novelas 'cuentos'. Estos se sabían de memoria, y nunca, que yo me acuerde, los vi escritos" (Novelas a Marcia Leonarda, ed. F. Rico, Alianza, Madrid, 1968, p. 27). Hay otros autores que intentan, sin embargo, diferenciar cuento/novela, pero M. Chevalier, editor de Cuentos españoles de los siglos xvi y xvii, Taurus, Madrid, 1982, p. 18, admite que "la frontera que separa ambos géneros parece de lo más borrosa". Del mismo autor, "Sur les notions de conte et de nouvelle au Siècle d'Or", Traditions populaires et diffusion de la culture en Espagne (xvie-xviie siècles), Bordeaux, 1981, t. 1, pp. 97-113. 
Pinciano. Tres se narran en la jornada inicial, protagonizado el primero por el vendedor de caballos que pretende estafar a un viajero (I, 2), el segundo por un andaluz que estafa a un vizcaíno durante su viaje hacia la corte (I, 4) y el tercero por un fraile que se burla de un caballero que de camino se aloja en el convento (I, 9). El cuarto cuento, interpolado al final de la última jornada (XVII, 5-6), está protagonizado por dos estudiantes que durante el viaje se hospedan en casa de dos hermanas moriscas. En función de la verosimilitud y del decoro, se origina una correspondencia entre las respectivas condiciones de los personajes de los cuatro cuentos interpolados y los del marco del diálogo, en el que Palatino y Pinciano conversan durante su viaje en las vacaciones. Sobre todo, en el último cuento de los Coloquios de Palatino y Pinciano, que es también el más elaborado literariamente, se manifiesta una clara correspondencia entre la condición estudiantil de los protagonistas del diálogo marco y la de los estudiantes que protagonizan la bur$\mathrm{la}^{24}$, a los que el narrador, Pinciano, dice conocer cuando alude a ellos como "dos amigos míos" (XVII, 5) que estudian también en la Universidad de Salamanca: "ahora tres años, se partieron de Salamanca dos compañeros como nosotros para irse a holgar las vacaciones a su tierra, que eran de Toledo". De nuevo subraya el narrador la coincidencia con los protagonistas de su relato al añadir: "Por el camino y en la primera jornada, se concertaron como nosotros cerca del gasto" (XVII, 5).

El argumento de los cuatro cuentos o novelas cortas gira en torno a una burla, más complicada de lo que es habitual en la fabliella y en el cuentecillo tradicional ${ }^{25}$. Está especialmente elaborada la burla que los dos estudiantes trazan para poder con-

${ }^{24}$ La adecuación entre el tono del relato y el carácter del narrador se produce de modo paradigmático en los Cuentos de Canterbury, la temática de los cuales depende de la condición social de los sucesivos narradores. Así, el caballero narra un relato amoroso con desafíos, el molinero ebrio cuenta el del estudiante y la mujer del carpintero; en respuesta, el mayordomo relata el de la molinera y los dos estudiantes. A su vez, el jurista narra la erudita historia de la infanta Costanza, el marino cuenta el del pícaro monje y la esposa del mercader. La priora refiere el piadoso martirio del hijo de la viuda a manos de los judíos, etcétera.

${ }^{25}$ La distinción la establece M. Chevalier, Folklore y literatura, pp. 71-72. Me refiero al desarrollo narrativo. Se pueden comparar las burlas de los cuatro cuentos o novelas cortas con la de los cuentos tradicionales que también aparecen en los Coloquios de Palatino y Pinciano, como el del estudiante medio echacuervo (VII, 6) o el de la nómina de la parturienta $(\mathrm{X}, 1)$. 
sumar sus relaciones adúlteras con las dos hermanas moriscas, burla que se complica más de lo habitual en los cuentos de casadas infieles ${ }^{26}$. A diferencia de lo que suele suceder en los cuentos de Boccaccio que giran sobre el motivo del adulterio, en el de Otálora la comicidad no resulta tanto de los engaños que traza la mujer para esconder al amante y de la credulidad del marido, como de las propias relaciones entre las dos adúlteras y sus respectivos amantes. Vamos a detenernos en este cuento con el que finalizan los Coloquios de Palatino y Pinciano, muy interesante para los orígenes de la novela corta en España.

Según cuenta Pinciano, dos estudiantes de Toledo que viajan desde Salamanca hacia su tierra se hospedan en casa de dos hermanas moriscas en la ciudad de Ávila, donde tienen que permanecer durante un tiempo a causa de un pleito con la justicia. Por una pragmática real27, el corregidor confisca la mula en la que viaja uno de los dos escolares, al que multa con diez mil maravedís. Hasta poder pagarlos, los estudiantes permanecen en casa de las dos moriscas recientemente casadas. Entre las dos parejas, se establece una atracción que finaliza en una cita amorosa nocturna, pero con un problema previo: el gusto en la elección de cada pareja está cruzado, como explica el narrador: "de ambas partes se conoscieron las buenas voluntades, salvo que estaban encontrados al contrario, porque el amo que había es-

${ }^{26}$ La tradición de los engaños de las mujeres, manifiesta en los cuentos de la séptima jornada del Decamerón, es de origen oriental, según apunta D. McGrady en la introd. a su ed. de las Novelas de Tamariz, Charlottesville, Virginia, 1974, p. 39. Hay varios ejemplos de este tipo de cuentecillo en la antología de Soons, núms. III, IXb, XII, XV: cf. M. J. LACARRA, "Algunos datos para la historia de la misoginia en la Edad Media", Studia in honorem prof. Martín de Riquer, Quaderns Crema, Barcelona, 1986, t. 2, pp. 339-361.

27 Coloquios de Palatino y Pinciano (XVII, 5): "les encontró el alguacil y preguntó al uno que iba en mula que si era clérigo o tenía caballo, que le mostrase testimonio de lo uno o de lo otro o que se fuese a la cárcel y dejase la mula”. La pragmática real debe de aludir a una serie que promulgan los Reyes Católicos, Libro de las bulas y pragmáticas de los Reyes Católicos, ed. facs., Instituto de España, Madrid, 1973, t. 2, ff. 280-284v: la primera de las cuales está dada en Granada, a 2 de mayo de 1493. Es una pragmática que ordena que "el que no toviere cavallo no pueda tener mula: y que si una vestia oviere de tener que sea cavallo salvo ciertas personas aquí exceptadas", que son los clérigos, y también licenciados y doctores, condiciones que no cumplen los estudiantes del cuento, ni tampoco Palatino y Pinciano, por lo que ambos viajan a caballo, como aclara Pinciano: "mis beneficios [no] bastan para andar a mula, pues no son en iglesia catedral ni colegial" (Coloquios I, 1). 
tado preso miraba a la mayor, que le contentaba más, y Ramírez, el criado, a la otra. Y ellas al revés, que la menor miraba al preso y la mayor, al suelto" (XVII, 5). Cuando la primera cita nocturna tiene lugar, los estudiantes intercambian sus respectivas señas de identificación para, amparados en la oscuridad, gozar de la morisca a la que desean, sin que ellas sospechen que en su cama se introduce el estudiante que no han elegido. Después de varias citas, Ramírez se ve forzado a marcharse de Ávila, lo que obliga a su compañero, el que se hace pasar por amo, a dejar de mantener relaciones sexuales con la hermana mayor que cree haber gozado con el ausente Ramírez. Al regreso de éste, se reanudan las citas siempre con el mismo engaño hasta que la hermana mayor se percata del cambio y decide, a su vez, burlar a los estudiantes con el mismo procedimiento. En la última cita, la morisca cambia los reclamos que cada una de las hermanas lleva para ser reconocida por su amante en la oscuridad. Cuando ellos deciden desvelar el engaño, la hermana mayor le hace creer a Ramírez que los dos estudiantes han sido engañados desde la primera noche.

Como en otros cuentos de los Coloquios de Palatino y Pinciano, el de los estudiantes y las moriscas se basa en una burla, complicada en este caso por el final que responde al clásico esquema del "burlador burlado" tan del gusto de los autores del siglo XvI porque, como dice uno de ellos: "el que quiere engañar a otro y se encuentra a la postre engañado es motivo de más risa que aquel que, sin molestar a nadie, resulta burlado"28. El cuento de Otálora sirve sobre todo para entretener, sin que se extraiga del relato moraleja o enseñanza alguna. Esta es una de las coincidencias más significativas entre el relato de Pinciano y las novelas de Boccaccio, con las cuales lo compara Palatino cuando concluye: "pase por novela de Juan Bocacio" (XVII, 6); ya antes había advertido Pinciano: "aunque os parezca novela de Juan Bocacio, pasó así” (XVII, 5). La comparación entre la novela de Boccaccio y la de los estudiantes se plantea en el texto como oposición a lo sucedido en la realidad. Así, en otro pasaje, Palatino ataja a su compañero diciéndole: "Aína me parecerá que se va haciendo una buena novela, al tenor de las de Juan Bocacio", a lo que contesta Pinciano: "Pues yo os digo que no es de ellas ni de otras, sino que pasó de hecho" (XVII, 5). Otálora rei-

28 Francesco Bonciani en la Lezione sopra il comporre delle novelle (1574), trad. M. J. Vega, p. 139. 
vindica la historicidad del argumento, al mismo tiempo que su originalidad con respecto al modelo italiano.

No se encuentra en el Decamerón la fuente libresca del último cuento de Otálora, a pesar de que sea posible establecer paralelismos con algunas novelas de la colección italiana cuyo argumento gira también en torno al motivo de la falsa seducción en la oscuridad ${ }^{29}$. No puede descartarse una posible fuente literaria del episodio de Otálora, que no he podido localizar aun contando con el útil repertorio de $\mathrm{S}$. Thompson y de otros catálogos en los que se encuentran clasificados motivos similares, como el de la "seducción por un impostor" o el de la "seducción por sustitución o por disfraz" ${ }^{30}$. En todo caso, la falsa seducción en la oscuridad aparece con relativa frecuencia en diferentes versiones, incluso con un desarrollo trágico ${ }^{31}$. La im-

${ }^{29}$ Hay en el Decamerón cuatro novelas en las que se aprovecha el motivo de la oscuridad para crear una confusión sobre la verdadera identidad de los amantes: el palafrenero del rey de los Lombardos se introduce de noche en el lecho de la reina suplantando al marido (X, 3); la viuda de Fiésole confunde a su presunto amante poniendo en su lugar a una sustituta (VIII, 4); la propia esposa, para poder consumar su matrimonio con el conde, se hace pasar en la oscuridad por la presunta amante (III, 9); Tito consuma su amor por la mujer del amigo haciéndose pasar por éste $(\mathrm{X}, 8)$.

${ }^{30} \mathrm{~S}$. Thompson, Motif-index of folk literature, Indiana University, Bloomington, 1956, "Seduction by disguise or substitution" (K 1310), "Seduction by imposter" (K 1315). No se documenta con ejemplos el motivo K 1856.1: "Mistress and maid unwittingly exchange lovers, each substitutes for the other"; cf. D. P. Rotunda, Motif-index of the Italian novella in prose, Indiana University, Bloomington, 1942, que trae a colación la novela de Francesco Sansovino, Cento novelle scelte da piú nobili scrittori dalla lingua volgare (I, 2), cuyo argumento se puede resumir así: "Gismondo ama Camilla, et ella per compiacere alla padrona, finge d'amar Giulio, e credendoselo meter in casa, vi mette Gismondo, et egli credendosi giacer con Camilla, giace con la padrona, laqual credendo dormir con Giulio dorme con Gismondo". He modificado el orden de los amantes masculinos, que está confundido en el ejemplar de la edición que manejo, Alessandro de Vecchi, Venecia, 1598. La novela de Sansovino, aunque no lo anota D. P. Rotunda, proviene de I Ragionamenti (1548) de Agnolo Firenzuola (I, 3). De esta última obra hay una edición moderna, Le novelle de A. Firenzuola, ed. E. Ragni, Salerno, Roma, 1971. Otro caso de intercambio de amantes es el motivo K 1317: "Lover's place in bed usurped by another" que aparece en las Nouvelles récréations (1558) de Bonaventure des Périers, núm. 54: la esposa de un mercader recibe de noche a su amante cuando éste, según la señal convenida, ladra en la calle. Un estudiante, que se percata de la señal, se adelanta al amante y le sustituye. Al final, los dos amantes se ponen de acuerdo para alternarse en el lecho de la esposa del mercader.

31 R. J. Clements y J. GiBaldy, Anatomy of the novella. The European tale collec- 
postura, tanto si la trazan hombres como mujeres, no se descubre hasta después de la consumación sexual. En su vertiente cómica, hay argumentos semejantes al de Otálora en las novelas ya citadas de Boccaccio y en las de otros novelistas, como A. Firenzuola: I Ragionamenti (1548).

El último cuento de Otálora sorprende por la construcción de la intriga y por la inmoralidad derivada de la misma, que nada tiene que envidiar a los relatos más procaces del Decamerón y de los novellieri. Entre los dos escolares y las dos moriscas, se produce un intercambio de parejas, un ménage à quatre podríamos decir. Mediante el engaño de la hermana mayor, cada una de las dos moriscas goza de los dos estudiantes y viceversa, pero en lugar de una condena moral o de un escarmiento, lo más sorprendente del "caso" que cuenta Pinciano a Palatino es que sirve sólo para entretenerse. Esta libertad moral resulta insólita en la narrativa española de la época y más aún en la posterior, aunque a veces se ha exagerado al hablar del carácter ejemplar de la novela española ${ }^{32}$. Es cierto que en la literatura castellana,

tion from Boccaccio and Chaucer to Cervantes, New York University Press, New York, 1977, p. 170, aducen otros ejemplos del motivo, que denominan "lover-in-the-dark theme also known as the fausse assignation", también presente en El burlador de Sevilla. La fausse assignation adquiere un desarrollo trágico en la novela de Juan Pérez de Montalbán, La mayor confusión, incluida en los Sucesos y prodigios de amor (1624), que presenta paralelismos con la novela XXX del Heptamerón de M. de Navarra y con la tradición italiana, por ejemplo, novela II, 35 de Bandello, y F. Sansovino, Cento novelle scelte (III, 4). En la versión de Montalbán, Casandra engaña a su hijo para gozar de él con engaños, ocupando de noche el lugar de la criada en su aposento. Véase Novelas amorosas de diversos ingenios del siglo xvii, ed. E. Rodríguez, Castalia, Madrid, 1987. Más semejanzas con la novela de Otálora hay en Giraldi Cinthio, Hecatommithi (I, 1), a pesar también del final trágico. El conflicto se origina entre dos hermanas meretrices (Frine, Caliene) y dos hermanos sicilianos (Tito, Talasso), pero la iniciativa corresponde a Frine, la cual usurpa en el lecho el lugar de la hermana. Cuando ésta descubre el engaño, Frine la envenena y acusa de su muerte a Tito.

32 Contrasta el cuento de Otálora con las novelas de Tamariz, por ejemplo, en las que a pesar de la abundancia de relaciones sexuales ilegítimas, hay una tendencia a extraer consecuencias morales de los relatos, como destaca D. McGrady en la introducción que he citado. La ejemplaridad se considera como característica de la tradición narrativa española, según la tesis que desarrolla W. PABst en su obra ya apuntada, La novela corta: "la tradición teórica de la novelística española, desde el siglo xII hasta Cervantes, tiene un nombre, y éste es exemplum" (p. 185); esta tesis que ha dado lugar a generalizaciones excesivas, como la de E. Leube, "Boccaccio y la novela corta europea”, Literatura universal. Renacimiento y Barroco, ed. A. Buck, Gredos, Madrid, 
permanece vigente el concepto de ejemplaridad, heredero de la tradición medievalizante. Como dice Lucas Gracián Dantisco en la traducción del Galateo español que publica en 1593: "Y tales pueden ser las novelas y cuentos, que allende del entretenimiento y gusto, saquen dellos buenos exemplos y moralidades, como hazían los antiguos fabuladores" (cap. 13, p. 155). Y en El Crotalón, leemos en el prólogo del autor al lector curioso:

Y porque tengo entendido el común gusto de los hombres, que les aplaze más leer cosas del donayre, coplas, chançonetas y sonetos de placer, antes que oýr cosas graves..., procuré darles esta manera de doctrinal abscondida y solapada debajo de façeçias, fábulas, novelas y donaires, en los quales tomando sabor para leer, vengan a aprovecharse de aquello que quiere mi intinçión. Este estilo y orden tuvieron en sus obras muchos sabios antiguos endreçados a este mesmo fin, como Ysopo y Catón, Aulo Gelio, Juan Bocaçio, Juan Pogio florentín, y otros muchos que sería largo de contar; hasta Aristóteles, Plutarco, Platón. Y Cristo enseñó con parábolas y exemplos al pueblo y a sus dicípulos la doctrina çelestial $^{33}$.

Este tipo de justificación moral predomina todavía en la narrativa renacentista excepto en casos como los cuentos y novelas cortas de los Coloquios de Palatino y Pinciano de los que no extrae moralidad alguna, sino que tan sólo sirven para entretener a los interlocutores durante los intervalos de ocio, en la línea inaugurada por Boccaccio. Aunque el marco de la obra de Otálora está caracterizado por su propósito didáctico, según es frecuente en el género de los diálogos, sin embargo, en los Colo-

1982, p. 13: "en la literatura narrativa española no se había interrumpido, desde la Edad Media, la tradición doctrinal-ejemplar"; tal peculiaridad se atribuye al "catolicismo profundamente arraigado" y a las disposiciones del "Concilio de Trento", como si ambos rasgos fueran exclusivamente españoles. En todo caso, hay algunas novelas que continúan el tono burlesco del cuento de Otálora, como la Novela de la comadre (1617) de Juan Cortés de Tolosa, cuya trama de estilo "boccaccesco", según subraya el editor moderno de la obra, presenta una "sustancial función humorística" (Lazarillo de Manzanares con otras cinco novelas de JuAn CortÉs DE Tolosa, ed. G. Sansone, Espasa-Calpe, Madrid, 1974, t. 1, p. xxxiv).

33 Cito por la edición de ANa Vian, Diálogo y forma narrativa en "El Crotalón": Estudio literario, edición y notas, Universidad Complutense, Madrid, 1982. De la misma autora, "El Crotalón: el texto y sus sentidos", NRFH, 33 (1984), 451-483. 
quios de Palatino y Pinciano la función risible de los relatos se desarrolla más de lo habitual. Los cuentos interpolados en las conversaciones de Palatino y Pinciano no sirven, en conjunto, para ilustrar el proceso de razonamiento o argumentación. Al contrario, los interlocutores de Otálora buscan, sobre todo, entretenerse con sus narraciones durante el camino, por lo que el marco didáctico funciona, con respecto al relato, de modo análogo a como funciona el marco del Decamerón: "to justify the possible questionable nature of his novellas" 34 .

Por otra parte, al final del cuento de los estudiantes y las moriscas, Pinciano plantea a Palatino varias preguntas en tono cómico. Por ejemplo, se trata de averiguar cuándo han disfrutado más los estudiantes: “¿cuál noche sería de más gusto: la que pensaba que gozaban con engaño o la que estaban desengañados?” (XVII, 6).Y también se pregunta, en el mismo sentido: “¿cuál es mayor contentamiento: gozar de la que no os quiere y vos queréis, o de la que os quiere y queréis?" (XVII, 6), e incluso: "si las moriscas quedaron preñadas, ¿qué parentesco ternán los que nacieren?" (XVII, 6). Sin embargo, Palatino pospone la respuesta a las preguntas de Pinciano ${ }^{35}$ : "No paséis adelante, que el cuento ha sido bueno y las dubdas son muchas, y hay que es-

34 Clements y Gibaldy, Anatomy of the novella, p. 43. Como es obvio, el marco narrativo del Decamerón es de naturaleza novelesca, a diferencia del de los Coloquios de Otálora, que pertenece al género del diálogo didáctico, estudiado como conjunto en mi tesis, El diálogo en el Renacimiento español, Cátedra, Madrid, 1988. No obstante, el calificativo de "didáctico" aplicado a los diálogos es discutido por otros investigadores, entre ellos A. Vian, quien encuentra más apropiado el de "argumentativo" incluso dentro de la tradición lucianesca. Esta hipótesis expuesta por Vian en varios de sus trabajos, como los antes citados, quizá encontraría más apoyo en otras tradiciones, por ejemplo, el diálogo filosófico según el modelo de Platón escasamente imitado en el siglo xvi español, o bien algunos diálogos renacentistas en los que se hace uso sistemático de procedimientos tomados de la lógica escolástica, como la Disputatio (1517) de H. Alonso de Herrera o el Diálogo de las cosas ocurridas en Roma de A. de Valdés. Cf. El diálogo en el Renacimiento espanol, pp. 43-52 y 86-92. En cualquier caso, las anteriores reflexiones carecen en la actualidad de una serie de estudios que acredite el corpus documental suficiente.

35 De las cinco intervenciones de Palatino durante el relato de Pinciano, en dos de ellas sus comentarios van dirigidos en el mismo sentido de acortar la narración: "Oyamos la conclusión, que luego se verá" (XVII, 5), dice en la tercera. En la cuarta: "Algo va larguillo el cuento; no será mucho que lleguemos a Salamanca primero que se acabe, que ya conocen la tierra las cabalgaduras y se dan priesa" (XVII, 6). 
tudiar en ellas para muchos días. Quédese la respuesta para otras vacaciones y pase por novela de Juan Bocacio" (XVII, 6). En las preguntas que plantea Pinciano sin propósito moral alguno, hay una parodia de los procedimientos habituales en la enseñanza universitaria de la época probablemente (no olvidemos que ambos estudiantes cursan derecho en Salamanca). Me refiero a la práctica escolar de las quaestiones, que dan lugar a la disputatio, sea en Artes, sea en asuntos jurídicos ${ }^{36}$. A este último ámbito corresponde la primera pregunta de Pinciano: "La primera es de derecho: si el corregidor era obligado a guardarles su previlegio y remitirlos al juez del estudio; y si la mula debía gozar del previlegio del que la llevaba para no ser castigada" (XVII, 6). En el resto de las preguntas que formula Pinciano también en tono cómico, se transparenta una parodia de las llamadas "cuestiones de amor", tradición cortesana y poética que se puede remontar hasta la literatura provenzal. Consiste en un juego de sociedad, paralelo al de contar novelas y facecias, en el que se formulan preguntas que pueden estar motivadas por los relatos amorosos oídos.

El procedimiento de los llamados dubbi y questioni d'amore está presente en el Decamerón (X, 5) y, de manera más extensa, en un episodio del Filócolo de Boccaccio, traducido al castellano desde 1546, que logra gran difusión en la literatura de la época, como advierte E. Asensio: "La difusión en Italia de las preguntas o dudas (questioni, dubbi) amorosas, vulgarizadas por el Filócolo de Boccaccio en la famosa escena del jardín junto a Nápoles, adaptadas por los tratados de amor, los poetas y novelistas alcanzó proporciones de epidemia social en saraos y academias"37. En España, este juego de sociedad se atestigua, por ejemplo, en El Crotalón, al describir las actividades que las damas desarrollan en el palacio de la bella Saxe (canto V): "solamente se ocupan en invenciones de traxes, justas, danças y vailes; y

36 Sobre la parodia de las cuestiones escolásticas, véase ahora F. LAYNA RANZ, "La disputatio burlesca. Origen y trayectoria”, Criticón, 64 (1995), 7-160.

37 Además, comenta E. Asensio, "Damasio de Frías y su Dórida, diálogo de amor. El italianismo en Valladolid", NRFH, 24 (1973), p. 231, que la costumbre penetró en España con la "novela de ambiente napolitano Questión de amor que Garcilaso rememoró en la Égloga primera, se insinuó en la Diana de Montemayor, en la Selva de aventuras de Jerónimo de Contreras y tocó de ligero a Lope de Rueda y a Timoneda”. El episodio del Filócolo (lib. 4) fue traducido al castellano por D. López de Ayala, Laberinto de Amor (1546), y editado en varias ocasiones durante el siglo XVI. Véase P. RAJNA, "L'episodio delle questioni d'amore nel Filócolo del Boccaccio”, Ro, 31 (1902), 28-81. 
otras, a la sonbra de muy apazibles árboles, novelan, motejan, ríen con gran solaz; qual demanda questiones y preguntas de amores..." Si, como asegura Asensio, la moda de las cuestiones de amor alcanza proporciones de epidemia social, conviene tener en cuenta que deriva de Boccaccio y de los novellieri 38 . Según atestigua G. Barbagli a fines del siglo xvi, hay dos maneras de disputa "que proceden del novelar", o bien se saca "materia de disputa de una sola novela" (como en la novela citada de la jornada décima del Decamerón), o bien la disputa se suscita cuando se comparan los casos narrados en novelas consecutivas $^{39}$. Por medio de las preguntas y de la discusión, en todo caso, se refuerza el vínculo entre los relatos breves y el diálogo marco. El procedimiento aparece en los Coloquios de Palatino y Pinciano no sólo en el último cuento, sino en un pasaje de la jornada decimocuarta, en el cual se relata otra anécdota de estudiantes que finaliza con una nueva pregunta: "Pregunto a vuestras mercedes cuál fue mejor librado" (XIV, 8). Del mismo modo, en la novela de los estudiantes y las moriscas, pregunta Pinciano (XVII, 5): "os quiero preguntar ciertas dudas que resultaron de un caso que acontesció a dos amigos míos con unas dos moriscas".

Según el modelo de Boccaccio, las preguntas y los debates unidos a las colecciones de relatos breves se desarrollan en los

38 Cita los siguientes ejemplos W. Pabst, op. cit., p. 33: "Los cuentos 14, 16, 17, 18, 21, 22, 29 y 37 de las Novelle di Gentile Sermini da Siena; en la segunda mitad del «Quattrocento» en Masuccio, y más concretamente en las cartas introductorias a las novelas cortas números 24, 26, 33 y 48 de su Novellino; en el «Cinquecento» (1550), en cuatro «questioni» de la segunda jornada de los Diporti del Parabosco; en los enigmas o adivinanzas, periódicamente repetidos, al término de las narraciones en las Piacevoli Notti (de 1550 en adelante) de Straparola; en una enumeración de juegos recogida en la introducción a los Trattenimenti de Barbagli”. Se podrían añadir I Ragionamienti de A. Firenzuola (1493-1543), ya citados, cuya primera edición es de 1548, véase el prólogo que Firenzuola dirige a la duquesa de Camerino.

${ }^{39}$ Dialogo de'Giuochi, p. 158: "No quiero dejar de decir que hay novelas de dos tipos: de unas se sacan dudas y cuestiones para disputar, otras, en cambio, no dan ocasión para la controversia. Las disputas que proceden del novelar surgen de dos maneras: o bien se saca materia de disputa de una sola novela, como fue la de madonna Dionora, que hizo que las mujeres arguyeran sobre quién fue más liberal con la mujer, el amante, el marido o el nigromante [Dec X, 5]; o bien suscitan la discusión dos novelas contadas una tras otra, cuando se dirime cuál de los dos hechos contados merece mayor alabanza". A este último esquema responde exactamente la questione que plantea el Condestable Álvaro de Luna en el Guzmán (segunda parte, I, 4). 
novellieri y fuera de Italia también, por ejemplo, en el Heptamerón (1558) de Margarita de Navarra, donde el procedimiento es utilizado de manera sistemática, ya que los interlocutores "dialogan y discuten al término de cada relato" 40 . Desde las novelas primera y segunda, M. de Navarra concibe su colección para animar el debate a favor y en contra de las mujeres. El motivo reaparece en algunas colecciones españolas de novelas cortas que se publican durante el siglo XvII, como los Diálogos de apacible entretenimiento de G. Lucas Hidalgo, las citadas Noches de invierno de Eslava o los Desengaños amorosos que María de Zayas publica en 1647, obras construidas también a imitación de Boccaccio aunque en ellas el propósito moral o ejemplarizante está más acentuado, algo que es habitual en la narrativa española de la época ${ }^{41}$. A pesar de las diferencias notables entre la finalidad de la novelística barroca y la de Boccaccio, el marco decameroniano ejerce una influencia visible en las novelas españolas tras la publicación de la obra de Eslava, como resume J. Barella: "La quinta de Florencia en el Decamerón dará paso a toda la serie de saraos, carnavales, huertas, jardines, cigarrales, y noches de invierno" 42 . Esta influencia se hace patente también en las preguntas y dudas que sirven para entrelazar el marco dialogado con el desarrollo narrativo de las novelle. Sucede, por ejemplo,

40 Como dice M. S. Arredondo, en la introd. a su trad. del Heptamerón de Margarita de Navarra, Cátedra, Madrid, 1991, p. 27.

${ }^{41}$ No hay más que recordar la frecuencia con que, a partir de las Novelas ejemplares (1613) de Cervantes, se repiten los calificativos de "morales" o de "ejemplares" en los títulos de las colecciones de novelas cortas: Cortés de Tolosa, Discursos morales (1617); D. Ágreda y Vargas, Novelas morales (1620), A. Liñán y Verdugo, Guía y avisos de forasteros... y debaxo de novelas morales y exemplares escarmientos (1620); F. Lugo y Dávila, Teatro popular: novelas morales (1622); G. Céspedes y Meneses, Historias peregrinas y exemplares (1623); J. Pérez de Montalbán, Sucessos y prodigios de amor en ocho novelas exemplares (1624); Juan de Piña, Novelas exemplares (1624); M. Velázquez, El filósofo del aldea, y sus conversaciones familiares y exemplares (1625); J. Pérez de Montalbán, Para todos, exemplos morales (1635); María de Zayas, Novelas amorosas y exemplares (1637); A. Alcalá y Herrera, Varios effetos de amor en cinco novelas exemplares (1641); C. Lozano, Soledades de la vida y desengaños del mundo, novelas y comedias exemplares (1662); I. Robles, Varios efectos de amor en onze novelas exemplares (1666), etc. Cf. B. Ripoll, La novela barroca. Catálogo bio-bibliográfico (1620-1700), Universidad, Salamanca, 1991.

42 J. Barella en la introd. a su ed. de Noches de invierno de Eslava, Gobierno de Navarra, Pamplona, 1986, p. 17. Dice M. Menéndez Pelayo, Orígenes de la novela, pp. 27-28: "El cuadro general de las novelas, tan apacible e ingenioso, y al mismo tiempo tan cómodo, se repite hasta la saciedad en los Ciga- 
en el Heptamerón y en las Noches de invierno, cuyas dos últimas novelas están animadas por la presencia del debate sobre la misoginia y el profeminismo. A su vez, los Desengaños amorosos están organizados como una tertulia en la que todos los narradores son mujeres obligadas a contar relatos que pongan de manifiesto las virtudes femeninas frente a la maldad de los hombres ${ }^{43}$. El propósito polémico se subraya mediante los apóstrofes y los comentarios dirigidos por las narradoras a su auditorio, con los que se acentúa la dimensión social y dialógica que adquiere el marco narrativo en las novelas de Zayas.

Sin necesidad de adentrarnos en el desarrollo del marco de Boccaccio y de la novela corta en España durante el siglo XVII, es el momento de volver a los Coloquios de Palatino y Pinciano que, dentro de la trayectoria esbozada, suponen una de las primeras tentativas por aclimatar en la práctica el modelo narrativo derivado del Decamerón. Entre los distintos tipos de novelas que se pueden distinguir en la colección italiana, no le interesa a Otálora el relato cortés, parodiado en las cuestiones de amor que hemos visto al final del cuento de los estudiantes y las moriscas. Palatino y Pinciano se inclinan por los relatos de burlas puramente cómicos, que en Boccaccio alternan con los idealizados y corteses ${ }^{44}$. Es un contraste paralelo en el Decamerón al

rrales de Toledo, del mismo Tirso; en el Para todos, de Montalbán; en la Casa del placer honesto, de Salas Barbadillo; en las Tardes entretenidas, Jornadas alegres, Noches de placer, Huerta de Valencia, Alivios de Casandra y Quinta de Laura, de Castillo Solórzano; en las Novelas amorosas, de doña María de Zayas; en las Navidades de Madrid, de doña Mariana de Carvajal; en las Navidades de Zaragoza, de don Matías de Aguirre; en las Auroras de Diana, de don Pedro de Castro y Anaya; en las Meriendas del ingenio, de Andrés de Prado; en los Gustos y disgustos del lentiscar de Cartagena, de Ginés Campillo, y en otras muchas colecciones de novelas, y hasta graves disertaciones, como los Días del jardín, del Dr. Alonso Cano".

43 María de ZaYas, Desengaños amorosos, ed. Alicia Yllera, Cátedra, Madrid, 1993, p. 118: "Fue la pretensión de Lisis en esto volver por la fama de las mujeres (tan postrada y abatida por su mal juicio, que apenas hay quien hable bien de ellas)". Por otra parte, la imagen de la tertulia femenina, reducida en este caso a un solo interlocutor, aparece implícita en el marco de las cuatro novelas de Lope, en los frecuentes comentarios que hacen depender el desarrollo narrativo de las supuestas preferencias femeninas, Novelas a Marcia Leonarda, pp. 34, 143, 178, etcétera.

${ }^{44}$ Relatos corteses y ejemplarizantes del Decamerón como, por ejemplo, el citado de Griselda (X, 10) o el del halcón de Fadrique (V, 9). A veces, este tipo de relatos se dan agrupados en una jornada, la décima y última, que ver- 
que se da en las Novelas ejemplares de Cervantes entre los relatos picarescos y los cortesanos, aunque sean estos últimos los que al parecer predominan en el devenir de la narrativa barroca ${ }^{45}$. Por último, conviene subrayar que, al margen de las numerosas diferencias, se pueden detectar semejanzas significativas entre la estructura del Decamerón y la de los Coloquios de Palatino y Pinciano, fundamentalmente porque Otálora utiliza en su obra el diálogo como marco del relato de entretenimiento. Además, el motivo del "alivio de caminantes" se encuentra en la narrativa de Boccaccio quien justifica el tono de su colección por la juventud y por el carácter de los interlocutores que aparecen, del mismo modo que Palatino y Pinciano son dos jóvenes estudiantes que disfrutan de vacaciones. En Boccaccio, pudo aprender Otálora a escribir el tipo de relato cuya finalidad reside en el puro placer de contar, sin moraleja explícita ${ }^{46}$. Hay otras obras escritas o editadas en castellano durante la primera mitad del siglo xvi que se pueden asociar al modelo narrativo derivado del Decamerón, como El Cortesano de Castiglione, El Crotalón o El Scholástico. Todas ellas son diálogos en los que se inter-

sa sobre "quién obró liberal o magníficamente". Esta jornada contrasta con otras de contenido exclusivamente burlesco y cómico, como la séptima que "trata de los engaños hechos por las mujeres a sus maridos" y la octava, "de los engaños que cada día la mujer hace al hombre o el hombre a la mujer, o que un hombre a otro hombre hace". En las restantes jornadas, se alternan los relatos de ambos tipos.

${ }^{45}$ Como señala C. B. Bourland, The short story, pp. 16-17: "Not all types of the Italian novella were equally popular in Spain; those imitated or borrowed are, as a rule, of a romantic or adventurous cast. Few imitations are found of those which recount the "piacevoli beffe» so often and so successfully played by women upon their husbands, or those whose points hinges upon a witly answer... and even in the inmoral stories borrowed the scrabous details were usually toned down or omitted". La tendencia moralizante aparece manifiesta, por ejemplo, en la práctica totalidad de los cuentos y novelas introducidos en el Guzmán de Alfarache, la mayoría de los cuales presenta una ambientación cortesana. Véanse también las novelas ya citadas de Camila y Leonardo en El viaje entretenido, de Eslava, de Lope, etc. que podrían servir para confirmar la opinión expuesta por Bourland.

${ }^{46}$ En otro pasaje de los Coloquios, cuando los estudiantes visitan el convento $(\mathrm{X}, 8)$, también se reúnen con las monjas y cuentan cuentos para entretenerlas. En el prólogo al Decamerón se advierte: “Tales historietas se cuentan, no en la iglesia... ni tampoco en las escuelas de los que profesan la filosofía... ni entre clérigos o filósofos en algún lugar reunidos, sino en medio de vergeles, en un solazoso paraje, entre personas mozas, aunque de bastante madurez para no dejarse doblegar por lo que se les cuenta”. 
calan relatos cuyo carácter festivo justifican los interlocutores como entretenimiento social, que va más allá del posible valor didáctico. Dentro de esta tradición, sobresalen los Coloquios de Palatino y Pinciano por la libertad moral con la que se introducen en ellos algunos cuentos y novelas cortas, algo que no parece que sea muy frecuente en la narrativa española ${ }^{47}$.

JEsús Gómez

Universidad Autónoma de Madrid

${ }^{47} \mathrm{~J}$. ARCE, Literaturas italiana y española frente a frente, Espasa-Calpe, Madrid, 1982, pp. 179-180: "Naturalmente que la prosa narrativa española nos ofrece series de narraciones breves, enlazadas entre sí con un pretexto, generalmente como contadas por personajes distintos que se reúnen en un lugar florido y deleitoso. Sin embargo, estas colecciones de cuentos, típicas del barroco español, suelen tener una intencionalidad específica completamente distinta de la del autor italiano, y aquí no puedo hacer otra cosa que dejar constancia de tal diferencia de actitud. Por ello, sigo pensando que el conocimiento de Boccaccio, masivo e indiscutible, no ha sido, a pesar de todo, tan determinante en la evolución de la literatura española como el de otros autores italianos". 